\title{
Standardized system for evaluating groundwater pollution
}

\author{
Khemmal Hichem Yakoub ${ }^{1}$, Hani Azzedine ${ }^{2}$ \\ 1 laboratoire : Unités de recherche des matériaux émergeants, université Ferhat \\ Abbas Sétif, Algérie.
}

\begin{abstract}
This paper presents a methodology that will permit the groundwater pollution potential of any hydrogeologic setting to be systematically evaluated. Pollution potential is a combination of hydrogeologic factors, anthropogenic influences and source of contamination in any given area. This methodology includes only the hydrogeologic factors which influence pollution potential.
\end{abstract}

\section{Introduction}

Groundwater has a major contribution to agricultural, industrial, drinking, and other municipal uses. The preparation of aquifer vulnerability maps has become crucial in recent years.

The DRASTIC method is a familiar method developed in the US Environmental Protection Agency (USEPA) by Aller et al. (1987) and this method has been applied in several regions by different researchers (Cameron and Peloso 2001; Al-Adamat et al. 2003; Baalousha 2006; Jamrah et al. 2007; Erhan S, et al. 2009; Ramaraju A, et al. 2019). It is the most commonly used overlay and index method all over the world, in Quebec 2018 this method was recommended by the ministry of the environment and fight against climate change to delineate wellhead protection areas.

Our objective is to achieve vulnerability assessment of groundwater using DRASTIC Method and the GIS techniques in the region of Setif which is located in the northeast of Algeria. DRASTIC layers were created during the preparation of the vulnerability map, using parameters such as groundwater level, recharge, aquifer environment, topography, and hydraulic conductivity. The aquifer vulnerability map was prepared by overlapping the layers using GIS.

\section{Method and materials}

\subsection{Drastic method:}

The name DRASTIC is taken from the initial letters of the seven parameters used to evaluate the intrinsic vulnerability of aquifer systems. The following symbols are used in the computation of DRASTIC vulnerability index.

A numeric value between 1 and 5 reflects the degree of influence of each of these parameters or their weight in the calculation of the indices. So the depth to water and the nature of the vadose zone exert the most critical influence, followed by recharge. Conversely, the topography is the parameter with the least impact, followed by the type of soil. Finally, the nature of the aquifer and its conductivity have a moderate weight. 


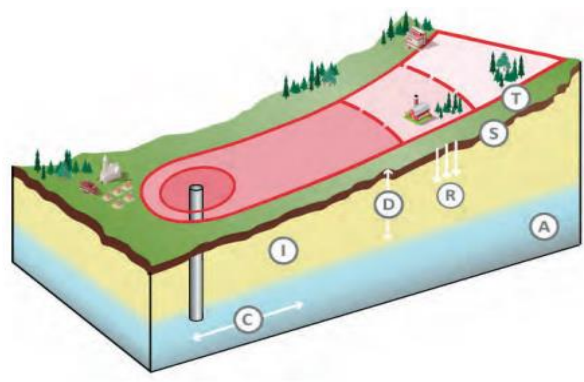

(A)

\begin{tabular}{|c|c|}
\hline Parameters & Weight \\
\hline Depth to water & 5 \\
\hline Recharge & 4 \\
\hline Aquifer media & 3 \\
\hline Soil media & 2 \\
\hline Topography slope & 1 \\
\hline $\begin{array}{c}\text { Impact of vadose } \\
\text { zone }\end{array}$ & 5 \\
\hline $\begin{array}{c}\text { Conductivity of the } \\
\text { aquifer }\end{array}$ & 3 \\
\hline
\end{tabular}

Figure 1: The DRASTIC method, its parameters and their weight

The determination of the DRASTIC index number is done by multiplying each parameter rating by its weight and adding together. Each parameter is rated on a scale from 1 to 10 , a rating of 10 indicating a high pollution potential of the parameter.

1. Table 1: the standard rating proposed by the DRASTIC method (Guide to conducting vulnerability analyzes of drinking water sources in Quebec)

\begin{tabular}{|c|c|c|c|c|c|c|c|}
\hline Rating & $\mathrm{D}$ & $\mathrm{R}$ & A & S & $\mathrm{T}$ & I & C \\
\hline & $\begin{array}{l}\text { Depth to } \\
\text { water } \\
\text { (m) }\end{array}$ & $\begin{array}{l}\text { Recharge } \\
\text { (mm/year) }\end{array}$ & Aquifer media & Soil media & Topography (\%) & $\begin{array}{l}\text { Impact of vados } \\
\text { zone }\end{array}$ & $\begin{array}{l}\text { Conductivity } \\
\text { (m/day) }\end{array}$ \\
\hline 1 & +31 & $0-50$ & & $\begin{array}{l}\text { Clay- } \\
\text { Limestone- } \\
\text { Marl }\end{array}$ & +18 & $\begin{array}{l}\text { Confident } \\
\text { layer(1) }\end{array}$ & $0.04-4$ \\
\hline 2 & $23-31$ & & Massive shale(1-3) & Black land & & Clay & $4-12$ \\
\hline 3 & $15-23$ & $50-100$ & $\begin{array}{l}\text { Igneous or } \\
\text { metmorphic } \\
\text { rocks(2-5) }\end{array}$ & Clay loam & $12-18$ & $\begin{array}{l}\text { Clay or silt(2-6) } \\
\text { schist }(2-5)\end{array}$ & \\
\hline 4 & & & $\begin{array}{l}\text { Altered igneous or } \\
\text { metmorphic } \\
\text { rocks(3-5) }\end{array}$ & Silitous loam & & $\begin{array}{l}\text { Igneous or } \\
\text { metmorphic } \\
\text { rocks(2-8) }\end{array}$ & $12-29$ \\
\hline 5 & $9-15$ & & Tillite(4-6) & Loam & $6-12$ & & \\
\hline 6 & & $100-180$ & $\begin{array}{c}\text { Limestone, shale } \\
\text { and sandstone beds } \\
(5-9) \text {. Solid } \\
\text { sandstone (4-9). } \\
\text { Solid limestone(4-9) }\end{array}$ & Sandy loam & & $\begin{array}{c}\text { Limestone(2-7) } \\
\text { Sandstone(4-8) } \\
\text { Sand and gravel } \\
\text { with silt and } \\
\text { clay(4-8) }\end{array}$ & $29-41$ \\
\hline 7 & $4,5-9$ & & & Cracked clay & & & \\
\hline 8 & & $180-250$ & $\begin{array}{c}\text { Sand and gravel(4- } \\
9 \text { 9) }\end{array}$ & Peat & & $\begin{array}{l}\text { Sand and } \\
\text { gravel(6-9) }\end{array}$ & $41-82$ \\
\hline 9 & $1,5-4,5$ & +250 & Basalt(2-10) & Sand & $2-6$ & Basalt(2-10) & \\
\hline 10 & $0-1,5$ & & Karst(9-10) & $\begin{array}{l}\text { Thin soil or } \\
\text { gravel }\end{array}$ & $0-2$ & Karst(8-10) & +82 \\
\hline
\end{tabular}

N.B: each material is classified according to the standard rating proposed by the drastic method. it also proposes a range of quotation indicated between () in this table.

The DRASTIC Index is then computed by applying a linear combination of all factors according to the following equation:

DRASTIC Index $=\mathrm{DrDw}+\mathrm{RrRw}+\mathrm{ArAw}+\mathrm{SrSw}+\mathrm{TrTw}+\mathrm{IrIw}+\mathrm{CrCw}$

The DRASTIC index can be further divided into four categories: low, moderate, high, and very high according to the Natural Breaks classification (Jenks):

- Low $(<100)$

- Medium (100-140)

- $\operatorname{High}(>140)$.

Each category reflects an aquifer's inherent capacity to become contaminated. The higher DRASTIC index number shows the greater relative pollution potential risk to one another. DRASTIC index is relative and dimensionless that depends on the geological and hydrogeological characteristics of an aquifer. 


\section{$2.2 \mathrm{GIS}$}

A geographic information system is a computer tool for representing and analyzing all the elements that exist on earth and all the events that occur there. A working methodology that consists in representing the collected information in the form of thematic maps, was carried out using Arcgis.

\section{Results}

\subsection{Depth to water:}

The observation of the water depth map reveals three different depth classes from:

- $15 \mathrm{~m}$ to $23 \mathrm{~m}$ around Kaaboub and Amusement Park.

- $23 \mathrm{~m}$ to $31 \mathrm{~m}$ around Ain Sfia

- $+31 \mathrm{~m}$ in the rest of the area.

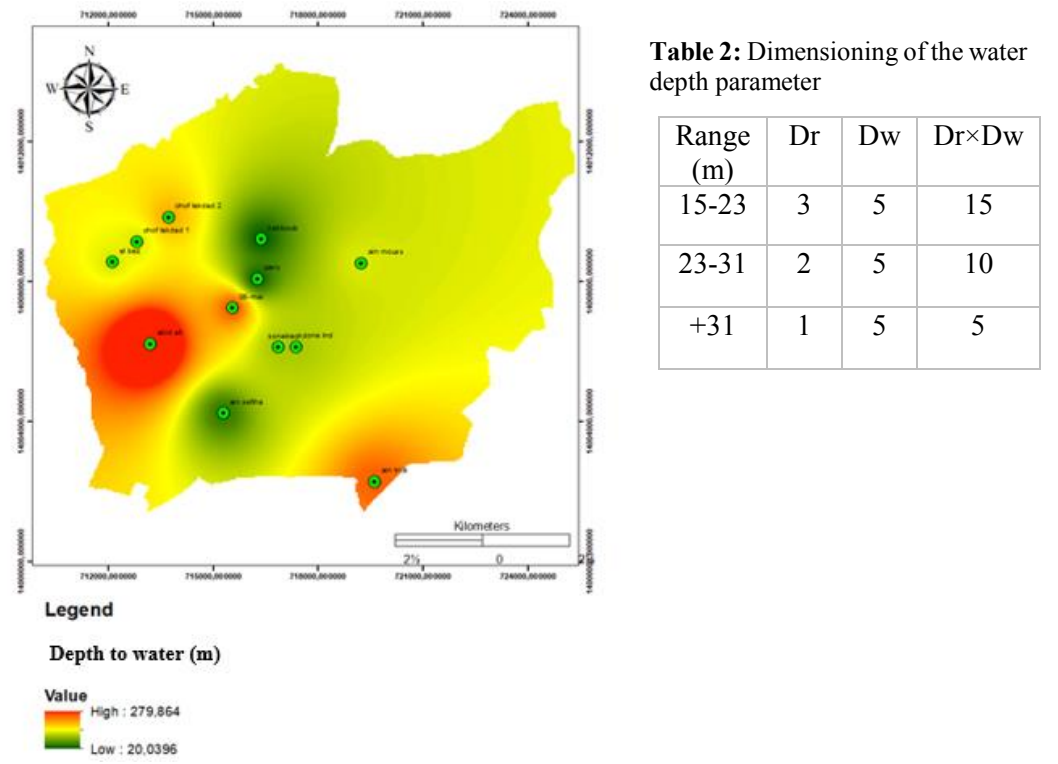

Figure 2: Depth to water rating map

\subsection{Recharge:}

Estimating regional recharge, or at the aquifer scale, is often sufficient for the purposes of calculating DRASTIC indices. Only one value can therefore be generally used (The Ministry of Sustainable Development, Environment, and Fight Against Climate Change: Guide to conducting vulnerability analyzes of drinking water sources in Quebec (2018)). Mapping the recharge area is the second step in identifying areas that may be affected by pollutants. The largest recharge areas are the most intolerable to contamination. The calculation leads to a value of $115 \mathrm{~mm} /$ year. The DRASTIC rating gives a rating of 6 for the range which is between $100 \mathrm{~mm} /$ year and $180 \mathrm{~mm} /$ year. We chose 4 because the calculated value is near to the range which has a rating of 3 . To do not inflate the recharge rating we chose the value of 4 . we would choose the rating of 6 if it was $\leq 150 \mathrm{~mm} /$ year. 


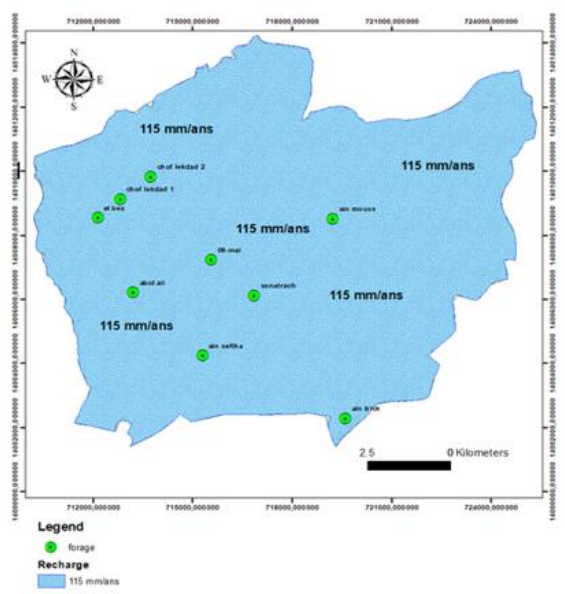

Figure 3: recharge rating map
Table 3: Dimensioning of the recharge parameter

\begin{tabular}{|c|c|c|c|}
\hline Range & $\mathrm{Rr}$ & $\mathrm{Rw}$ & $\mathrm{Rr} \times \mathrm{Rw}$ \\
\hline $\begin{array}{c}115 \\
(\mathrm{~mm} / \text { year })\end{array}$ & 4 & 4 & 12 \\
\hline
\end{tabular}

\subsection{Aquifer media:}

The typical rating can be used if a little knowledge is available about the hydraulic properties of the formation. Otherwise, a choice in the range of the ratings must be made. For rock aquifers, it is usually the fracturing level that must be taken into account. For granular aquifers, it is the granulometry and the homogeneity of the sediment which must be taken into account. It's obvious that permeable formations have a higher rating score than low permeability and impermeable formations. The DRASTIC method gives a range from 9 to 10 to karst formations, we chose the rating 9 because of the presence of marl in the fractured karst.

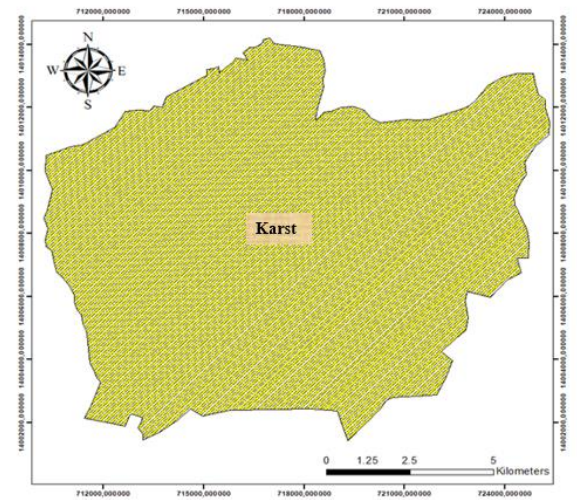

Figure 4: Aquifer media rating map
Table 4: Dimensioning of the aquifer media parameter

\begin{tabular}{|c|c|c|c|}
\hline Formation & Ar & Aw & $\mathrm{Ar} \times$ Aw \\
\hline Karst & 9 & 3 & 27 \\
\hline
\end{tabular}

\subsection{Soil media:}

Throughout our study area, the surface of the ground by its impermeable nature plays a role of protector against the infiltration and the evolution of the pollutant on the contrary in the south-west part the surface of the ground is characterized by the Sandy clay that is a little permeable. The drastic method gives a rating of 1 to clay and 9 to sand we chose the rating 4 for this formation. 


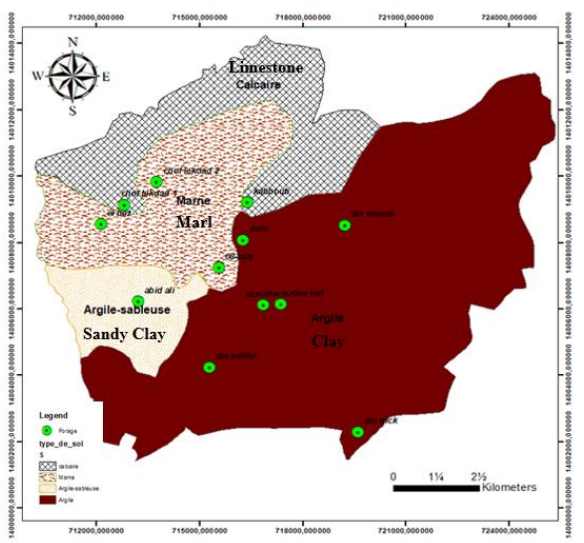

Table 5: Dimensioning of the soil media parameter

\begin{tabular}{|c|c|c|c|}
\hline Formation & $\mathrm{Sr}$ & $\mathrm{Sw}$ & $\mathrm{Sr} \times \mathrm{Sw}$ \\
\hline Limestone & 1 & 2 & 2 \\
\hline Marl & 1 & 2 & 2 \\
\hline $\begin{array}{c}\text { Sandy } \\
\text { Clay }\end{array}$ & 4 & 2 & 8 \\
\hline Clay & 1 & 2 & 2 \\
\hline
\end{tabular}

Figure 5: Soil media rating map

\subsection{Topography:}

It has an influence on the infiltration and therefore the spread of the pollutant. The delimitation of the zone is based on the observation of a numerical model of elevation. Three classes were observed:

- From 6\% to 12\%: in the southern part of the town of Sétif. The slope does not have a great value in this area which is a part of high plains Setifian

- From $12 \%$ to $18 \%$ : in the center of the town of Sétif. It's the area that separate between high mountainous and high plains.

- $\quad+18 \%$ : in the northwestern part of the town of Sétif which is known as a mountainous area. The slope in this area has a significant value.

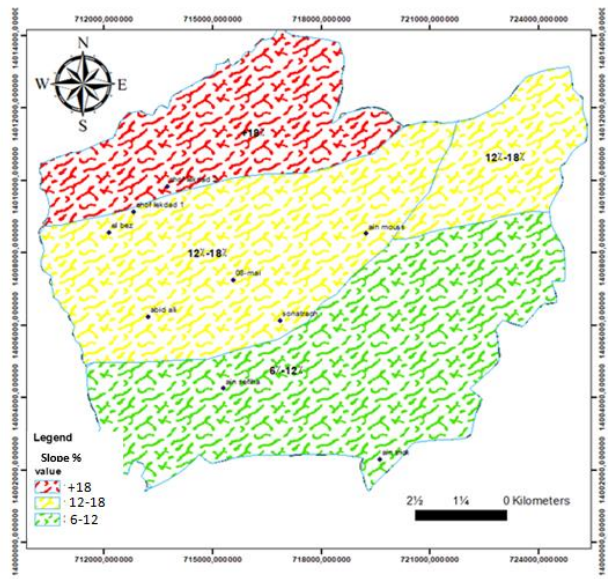

Figure 6: Slope rating map
Table 6: Dimensioning of the topography parameter

\begin{tabular}{|c|c|c|c|}
\hline Range(\%) & $\operatorname{Tr}$ & $\mathrm{Tw}$ & $\operatorname{Tr} \times \mathrm{Tw}$ \\
\hline $6-12$ & 5 & 1 & 5 \\
\hline $12-18$ & 3 & 1 & 3 \\
\hline+18 & 1 & 1 & 1 \\
\hline
\end{tabular}

\subsection{Impact of vadose zone:}

The same conditions concerning the standard values of the parameter on aquifer media are applied.

The rating range for clay formations varies between 2 and 6 according to the formation which is included with it and its permeability.

- We chose the rating 4 for limestone because of its low fracking.

- The marl is $50 \%$ limestone and $50 \%$ clay which gives a rating of 4 for this formation. 
- We chose the rating 3 for the formation marl-limestone because of the nature of limestone in the central south of Setif which is hard.

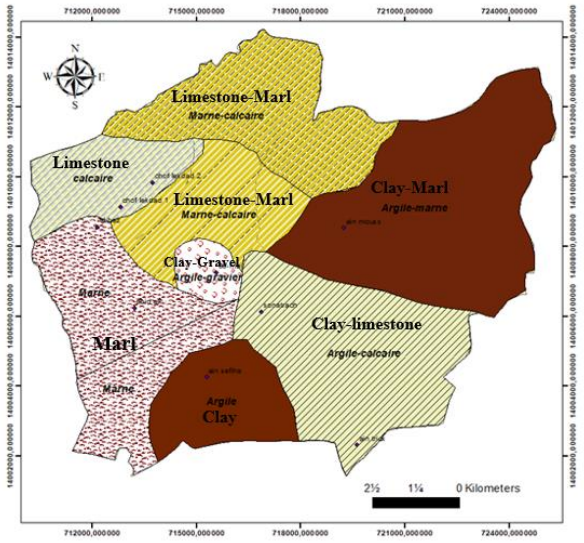

Figure 7: Impact of vadose zone rating map

Table 7: Dimensioning of impact of vadose zone parameter

\begin{tabular}{|c|c|c|c|}
\hline Formation & Ir & Iw & $\mathrm{Ir} \times \mathrm{Iw}$ \\
\hline Clay & 2 & 5 & 10 \\
\hline $\begin{array}{c}\text { Clay'n } \\
\text { Limestone }\end{array}$ & 4 & 5 & 20 \\
\hline Marl & 4 & 5 & 20 \\
\hline $\begin{array}{l}\text { Clay'n } \\
\text { Gravel }\end{array}$ & 6 & 5 & 30 \\
\hline $\begin{array}{c}\text { Clay'n } \\
\text { Marl }\end{array}$ & 3 & 5 & 15 \\
\hline Limestone & 4 & 5 & 20 \\
\hline $\begin{array}{c}\text { Marl- } \\
\text { Limestone }\end{array}$ & 3 & 5 & 15 \\
\hline
\end{tabular}

\subsection{Conductivity:}

The conductivity of the aquifer is between $0.04 \mathrm{~m} / \mathrm{d}$ and $14 \mathrm{~m} / \mathrm{d}$. The observation of the conductivity map shows two classes:

- from $0.04 \mathrm{~m} / \mathrm{d}$ to $4 \mathrm{~m} / \mathrm{d}$ in the center of the town of Sétif.

- From 4 to $12 \mathrm{~m} /$ day away from the center, the permeability increases.

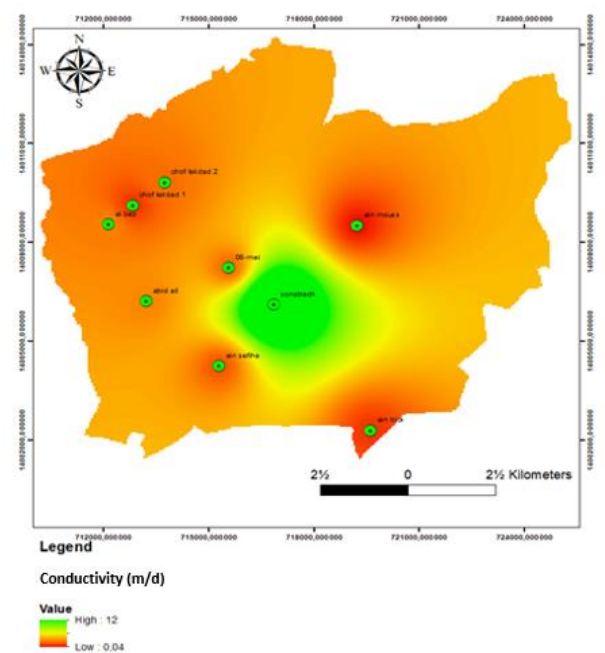

Table 8: Dimensioning of conductivity parameter

\begin{tabular}{|c|c|c|c|}
\hline $\begin{array}{c}\text { Range } \\
(\mathrm{m} / \mathrm{d})\end{array}$ & $\mathrm{Cr}$ & $\mathrm{Cw}$ & $\mathrm{Cr} \times \mathrm{Cw}$ \\
\hline $\begin{array}{c}0.04- \\
4\end{array}$ & 1 & 3 & 3 \\
\hline $4-12$ & 2 & 3 & 6 \\
\hline
\end{tabular}

Figure 8: Conductivity rating map

\subsection{DRASTIC index map:}

The following figure illustrates DRASTIC INDEX MAP in the commune of Setif. Each of DRASTIC parameters has been expressed as thematic layer using ArcGIS. All generated maps were used to assess intrinsic groundwater vulnerability to pollution. Only one zone of vulnerability was determined in the commune of Setif.

According to the DRASTIC scores in the vulnerability map $100 \%$ of the study area have a low potential for contamination which is between 68 and 89 .

The highest value of the vulnerability is located in the center of the commune because of the low depth of the water table and the nature of the vadose zone which is permeable. 


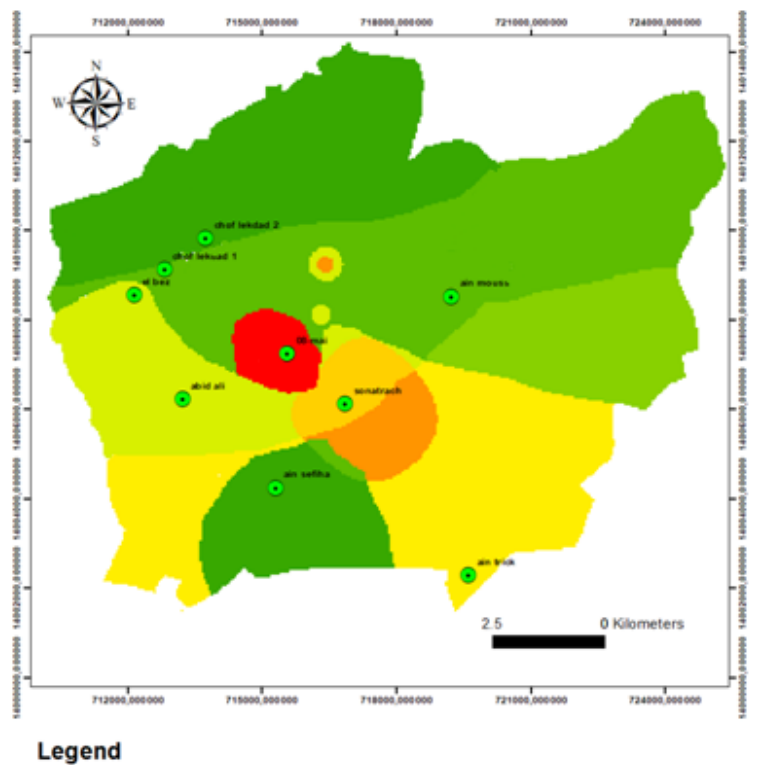

\section{DRASTIC index}

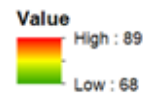

Figure 9: DRASTIC INDEX MAP in the commune of Setif

\section{Conclusion}

This method was prepared to assist planners, managers and administrators in the task of evaluating the relative vulnerability of areas to groundwater contamination from various sources of pollution. Once this evaluation is complete, it can be used to help direct resources and land use activities to the appropriate areas. This methodology includes also the creation of a system which can be readily displayed on map.

It is obvious that all the drastic parameters interact, dependent variable. Their selection is based on quantitatively developed and rigorously applied data coupled with a subjective understanding of real-world conditions in a given area.

Finally, we present an effective and economical protocol for assessing groundwater vulnerability and thus planning human activities.

\section{References}

1. Aller L., Benett T., Lehr J.H. and Petty R.J., (1987). DRASTIC: a standardized system for evaluating ground water pollution potential using hydrogeologic settings. Office of Research and Development, Environmental Protection Agency USA.

2. The Ministry of Sustainable Development, Environment, and Fight Against Climate Change (2018). Guide to conducting vulnerability analyzes of drinking water sources in Quebec 